\title{
Colectivos y redes de maestros: campo constituyente de sujetos de saber pedagógico y de acción política*
}

\author{
María Cristina Martínez Pineda ${ }^{1}$
}

\section{Resumen}

El texto aborda los modos como los colectivos y redes pedagógicas de maestros se han venido constituyendo, desde perspectivas autónomas y agenciadas por los mismos maestros, en formas alternativas a la problemática sobre la formación y actualización permanente de los maestros en ejercicio. En este orden, además de hacer visible las experiencias y actuaciones de maestros y maestras que se han organizado con fines pedagógicos para construir otras formas de ser maestro en Colombia, coloca en escena elementos que aportan a una reflexión crítica sobre los diseños y modos de intervención para la formación de maestros que se continúan imponiendo externamente, a la vez que abre caminos para animar la continuidad y sostenibilidad de estas formas de colectivización y el surgimiento de nuevos movimientos culturales y sociales.

Las preguntas que atraviesan el contenido son: ¿Los procesos e interacciones que se están generando en las redes pedagógicas posibilitan la potenciación y actuación del maestro como actor de cambio social y político? ¿Cuál es el alcance de las acciones que realizan los maestros de las redes pedagógicas?

Su desarrollo se hace en cuatro apartados: el primero describe de manera sucinta la situación-problema, el segundo, esboza las nociones de red pedagógica y su emergencia en Colombia, el tercero desarrolla y fundamenta, desde una mirada empírica, los alcances de las redes, y el cuarto apartado abre la discusión acerca de las capacidades que se están potenciando y lo político en la actuación de los maestros que participan.

Palabras clave: Redes pedagógicas, Colectivos de maestros, Sujeto político, Subjetividades políticas, Maestros del límite, Transformaciones pedagógicas

\section{Summary}

The text deals with the ways teachers groups and pedagogical networks have became alternative forms of teachers formation, and up date of curren teachers from autonomouns perspective. It simultaneously places in scene elements for the critical reflection on the designs and ways of intervention for the formation of teachers which they are externally continued imposing, that lays ways to cause the sustainability of these forms of colectivization and the agency new cultural and social movements.

The questions that cross the content are: Do make such processes and interactions the teachers empowerment and performance as political and social change agent? ¿Which is the reaching of actions carried out by teachers? Are being harnessed other capacities?

Its development becomes in four sections: first outlines the situation-problem; the second, one the slight knowledge of pedagogical network as much in its emergency; third develops and bases, with the empirical glance the capacities that are harnessed in the teachers and the fourth opens the discussion about the political in the performance of teacher.

\footnotetext{
* Los planteamientos y la argumentación que sostienen el desarrollo de este texto se documentan en la investigación que la autora viene realizando sobre las redes y colectivos de maestros como experiencias dinámicas de formación autónoma y de agenciamiento de su capacidad de acción política, especialmente en el departamento de Santander. Texto recibido el 27 de julio y arbitrado el 11 de agosto de 2004.

1 Profesora-investigadora de la Universidad Pedagógica Nacional. Jefe Departamento de Posgrados. Miembro de la Expedición Pedagógica Nacional. E-mail: mmartinez@uni.pedagogica.edu.co 
Key words: Pedagogical networks, Collective of teachers, Teacher networks, Political subject, Political subjectivities, Border teachers, Pedagogical changing.

\section{El punto de partida: situación-problema}

La formación permanente de los educadores se ha convertido en un campo de debate en el país. Por años hemos repetido, de un lado, que para efectos de los ascensos en el escalafón docente ${ }^{2}$ se impuso la feria de créditos sin efectos reales en la transformación de procesos pedagógicos y en los maestros participantes; y de otro, que los programas orientados oficialmente buscan prioritariamente instruir al maestro para que en la mediación curricular obedezca acríticamente e introduzca los arreglos y las decisiones preestablecidas y dictadas desde los organismos internacionales que diseñan las macropolíticas. En ambos casos, los maestros participantes se ven como receptores de dichos programas y no como sujetos activos, generadores y productores de los mismos. Es decir, oficial e institucionalmente se ha negado e invisibilizado el maestro como actor capaz de ser protagonista de su propia transformación y cualificación. Adicionalmente, a este modo de lectura subyace otro menos visible: el sujeto configurado como maestro responde a unas lógicas de formación también impuestas que se reproducen o potencian en la formación de individuos dominados, repetitivos y apáticos. Ello porque no se han producido en los maestros y maestras esas refundaciones mismas de los modos de constituir subjetividades de resistencia, transformadoras del orden global, social y económico establecido.

Una alternativa a esta realidad que se ha venido agenciando en el país durante más de dos décadas, digamos que desde el movimiento pedagógico, ha reconocido y hecho visible múltiples experiencias y actuaciones de maestros y maestras que de manera autogestionaria han venido construyendo otros modos de ser y otras formas de actuación que amplían la mirada que se tiene de ellos mismos. Éste ha sido el lugar de los colectivos y redes pedagógicas que, como expresiones de organización de los maestros en torno a la pedagogía, han visibilizado a un sujeto capaz de decidir, proponer e intervenir en sus propios procesos de mejora y en los de su contexto social y cultural.

Si bien es incontable la producción escrita que existe acerca de la formación permanente de educadores, quiero advertir que este texto no surge de otros textos, sino de la interacción directa con colectivos de maestros y maestras y del seguimiento empírico a sus actuaciones y producciones durante varios años; por tanto, no está totalmente construido y quiere profundizar en las preguntas que lo originan.

\section{El lugar de las redes pedagógicas en la formación del profesorado}

\subsection{Aproximaciones para un concepto de red pedagógica}

El concepto de redes pedagógicas surge en Colombia para referirse a grupos de maestros que se convocan especialmente para reflexionar sobre su papel, sus alcances, sus realidades, a fin de interpretarlas y reconstruirlas. Estos grupos se constituyen generalmente por unidad de intereses que pueden ser: una temática específica (maestros de preescolar), un área de conocimiento (maestros de matemáticas), la problemática de una zona (maestros rurales), un programa específico (red ambiental). Sea cual fuere la

\footnotetext{
${ }^{2}$ Me refiero al escalafón para los educadores de educación básica media, decretos 2277 de 1979 y 1278 de 2002, expedidos por el MEN.
} 
iniciativa de organización, los maestros elaboran un plan interno de trabajo, construyen su propia dinámica de desarrollo y buscan conectarse, establecer interacción -en red-con otros maestros y otros colectivos.

Para Martínez y Unda,

(...) Se trata de redes de personas que buscan potenciar su capacidad de acción, reconociendo y valorando la diversidad y la autonomía, diagramas de fuerzas que nos conectan de otros modos menos burocráticos, no jerarquizados, no ordenados (...) Otro modo de ser conjuntos, es una manera de recuperar el poder para nosotros mismos, son conexiones y diagramas en donde las fuerzas circulan de modo tal que se instauren justas distancias no jerárquicas sino geométricas (5-6).

Para la Expedición Pedagógica ${ }^{3}$, las redes pedagógicas se ven como una expresión de la posibilidad de generar políticas que respondan a las realidades regionales y a la necesidad de construir nación desde la educación. Se resalta en ambos casos la importancia de impulsar procesos de participación en la definición de políticas educativas, así como la necesidad de fortalecer vínculos entre las organizaciones para ampliar su perspectiva de actuación como sujeto colectivo, a fin de romper los bloqueos de la formación individual y fortalecer equipos que trabajan conjuntamente.

Las redes o colectivos se constituyen entonces en territorios de construcción y contrastación, donde sucede la doble mirada del maestro: a su mismidad, en tanto que allí, en acción reflectiva -mirada espejo- puede verse en los otros, encontrar-se, contrastar-se, confrontar-se, preguntar-se, contextualizar-se, y a su devenir como sujeto en construcción continua. Es en esta doble mirada que suceden y se gestan las formas emergentes de ser y de actuar, porque el sujeto se deconstruye y reconstruye en una acción continua que, a la vez que lo potencia, transforma sus actuaciones, lo afirma como sujeto público y le abre otros escenarios públicos. En las redes, el maestro construye otra ruta pedagógica, se anima, se fortalece e incentiva su creatividad. Ahí suceden las caídas en cuenta, las líneas de fuga, la polifonía de voces, que son capaces de romper los monólogos impuestos como verdades únicas para un país pluriétnico y multicultural, y se hace visible la singularidad y la potencia de ser maestro.

Con estos precedentes, asumo la noción de red pedagógica como unidad de significación que se convierte en campo de constitución de sujetos y saberes desde tres ámbitos: como estrategia de formación permanente, como movimiento social y cultural y como potenciación del maestro como sujeto político.

Como estrategia de formación permanente, porque en colectivo se promueve la ruptura de la concepción piramidal y jerárquica que ha predominado en la orientación de estos programas. En red, porque no se trata sólo de que los integrantes participen sino que sean protagonistas, actores, autores y corresponsables de su propio proceso de cualificación. Se trata, como expresan Martínez y Unda (1995), "de producir una ubicación diferente del maestro que lo coloque en un diagrama de fuerzas en el cual su función supere y trascienda la condición de operario a la que ha sido reducido" (94), o como plantea Dabas, el lugar donde "cada miembro del colectivo se enriquece a través de las múltiples relaciones que cada uno de los otros desarrolla, optimizando los aprendizajes al ser éstos socialmente compartidos".

\footnotetext{
${ }^{3}$ La Expedición Pedagógica se asume como una movilización cultural por la educación, y se adelanta en Colombia desde 1999. Su recorrido se ha hecho por más de 192 escuelas y 22 departamentos, y ha hecho visible, entre otros aspectos, los diversos modos de ser maestro, hacer escuela y construir pedagogía. 
Como movimiento social y cultural en tanto posibilitan y favorecen la creación de tejido social, porque en las interacciones van articulando y cohesionando intereses, esfuerzos, inconformidades y búsquedas compartidas para construir colectivamente nuevos imaginarios y modos de actuación. También, porque se constituyen en estrategia de participación que permite a los actores educativos reflexionar sobre las problemáticas educativas y pedagógicas e intervenir en la toma de decisiones sobre lo público. En este caso, las redes propician los enlaces dialogantes e interconexiones no directivas que son aspectos constitutivos de un movimiento social.

Como potenciación del maestro y la maestra como sujeto político, en el sentido que plantean Touraine (1997) y Arendt (1997), como actores y autores que, fortaleciendo su sí mismo individual y colectivo, potencian su capacidad de discurso y acción para participar en proyectos individuales y colectivos de carácter transformador. Al constituirse las redes en lugares instituyentes, no impuestos ni reglados, a los que se llega por deseo y voluntad propia, posibilitan que los sujetos se piensen de otra manera, y por tanto, resignifiquen sus relaciones y modos de interacción con sus pares y con el saber pedagógico. Se trata entonces de un campo desde el cual es posible que los maestros, como sujetos, se transformen y simultáneamente generen transformaciones pedagógicas, culturales y sociales, desde perspectivas más democráticas, y se constituyan en actores y autores con capacidad para establecer conexiones, relacionarse e intervenir en la definición de políticas educativas, generar propuestas alternativas que incidan correlativamente en su propio desarrollo y en el desarrollo institucional y local.

¿Cómo funcionan? En las redes, se generan interacciones e interrelaciones colaborativas, se rompen las jerarquías piramidales tradicionales en las formas comunes de asociación ${ }^{4}$, y se promueven relaciones horizontales de coordinación colegiadas en las que se exploran y aprovechan las potencialidades de cada uno de sus integrantes y se asume corresponsabilidad en las acciones. Así, las actividades colectivas dependen de la iniciativa de cada una de sus partes, nudos o nodos y no de una instancia central y única.

¿Cuándo se llega al estatuto de red pedagógica? Si bien se trata de lugares construidos autónomamente, es necesario advertir que no toda organización de maestros se eleva a la categoría de colectivos o redes pedagógicas. Para avanzar en esta diferenciación, se establecen al menos cuatro condiciones: i) su interés colectivo es educativo y pedagógico; ii) realizan acciones colectivas conectadas - preferiblemente- con su trabajo individual; iii) han definido modos y momentos de interacción y estrategias de comunicación y circulación de saberes; iv) sus integrantes se asumen como productores de saber pedagógico y, por tanto, como actores de cambio pedagógico y sociopolítico.

\subsection{Emergencia y trayectoria de las redes en Colombia}

La emergencia y el desarrollo de redes pedagógicas de maestros obliga a rastrear las diferentes formas de organización pedagógica que han tenido en los últimos 15 años los maestros y maestras en Colombia. La Expedición Pedagógica da cuenta de cinco factores que sirven como antecedente y como hechos potenciales de este fenómeno:

El Movimiento Pedagógico ${ }^{5}$ emprendido por un grupo de maestros colombianos agrupados en su organización sindical, la Federación Colombiana de Educadores -

\footnotetext{
${ }^{4}$ Una diferencia con el concepto tradicional de asociación está en que en la red no se requieren estatutos ni patrones de comportamiento establecidos para la acción y la asociación.

${ }^{5}$ El Movimiento Pedagógico nació en las organizaciones del magisterio colombiano en 1982, y se definió como una estrategia política y cultural de los maestros colombianos para contribuir a crear la conciencia Digitalizado por RED ACADEMICA
} 
Fecode-, ha sido uno de los referentes más importantes de las formas emergentes de colectivización y de organización pedagógica de los educadores para su constitución como sujeto colectivo. Este movimiento, como hecho singular de nuestro país, ha dado lugar a múltiples experiencias en esta dirección.

La Ley General de Educación de 1994 y las políticas educativas derivadas. Su espíritu democratizador legitimó algunas iniciativas de participación existentes y animó la conformación de otras como los comités estudiantiles, los consejos académicos, las organizaciones de padres de familia, el desarrollo de proyectos pedagógicos transversales que convocaron al encuentro de maestros por áreas y que sirvieron para avanzar en la superación de currículos homogéneos. Colectivos que, si bien, en la mayoría de los casos surgieron por norma, algunos lograron dinámicas diferentes y se convirtieron en posibilidades de conectar maestros de diferentes disciplinas y de establecer otros diálogos.

La crisis de los programas de formación de maestros. Este hecho-problema ha suscitado tantas críticas como propuestas alternativas; entre éstas citamos los colectivos y redes de maestros organizados, unos de manera autogestionaria, otros convocados por organizaciones educativas o universidades, unos como extensión de sus proyectos y otros como estrategia para diversos fines.

Los procesos de acreditación de las Escuelas Normales. Esta dinámica ha generado diferentes formas de autoorganización de los maestros, equipos, comisiones y otras expresiones surgidas de la interacción con otras Normales e instituciones y con facultades de Educación. Algunas han ido consolidándose y se han instalado en la cotidianidad institucional.

Proyectos originados a partir del apoyo a innovaciones por parte del Ministerio de educación -MEN- y por propuestas oficiales. El reconocimiento de las iniciativas de los maestros por cualificar las prácticas pedagógicas y la entrada al MEN y secretarías de Educación de personas con intereses de este orden, han promovido y hecho explícito el deseo de organizar redes de maestros y directivos docentes, especialmente con el interés de reconocer los trabajos de innovación e investigación de los maestros para difundirlos ${ }^{6}$ (89-91).

Digamos entonces que la colectivización de los maestros no es una acción novedosa en este país: su trayectoria se registra sistemáticamente desde 1980, tiempos de iniciación del movimiento pedagógico, con múltiples y variadas experiencias que dan cuenta de esta forma de organización y colectivización con intereses pedagógicos.

En la última década, varios hechos dan cuenta de este avance: los cinco encuentros nacionales de redes pedagógicas que se han adelantado en el país y que han convocado a centenares de grupos organizados de maestros, cuyas memorias han sido registradas en la revista Nodos y Nudos de la Red CEE de la Universidad Pedagógica; los tres encuentros iberoamericanos de redes y colectivos en los que el país ha participado como convocante, junto a otras redes ${ }^{7}$. En la misma dirección, se suman los hallazgos de la

\footnotetext{
histórica de una nueva escuela y una nueva sociedad, y para hacer visible el papel de los maestros como trabajadores de la cultura.

${ }^{6}$ Ejemplos concretos pueden verse en la convocatoria al reconocer experiencias exitosas en los diferentes departamentos. En Santander cabe citar el programa de lengua materna que logró convocar y conectar alrededor de 700 maestros; el programa de maestros investigadores promovido por la Secab que reunió 300 maestros en Santander y conectó las redes de varios departamentos. Algunas de estas experiencias lograron consolidarse y sostenerse concluido el período de acompañamiento.

${ }^{7}$ Las redes Iberoamericanas que han convocado estos encuentros son: por Colombia, desde el Proyecto Red CEE -Red de cualificación de educadores en ejercicio- de la Universidad Pedagógica Nacional; por México, Red TEBES -Red para la transformación de la educación básica desde la escuela-; por Argentina, Red DRIE; por España, Red IRES RED -Red para la investigación y renovación escolar-. El tercer Digitalizado por RED ACADEMICA
} 
Expedición Pedagógica, que dan cuenta de más de 60 organizaciones pedagógicas que incluyen redes, grupos de estudio, de investigación, de discusión, comisiones pedagógicas, centros de investigación de docentes -CEID-, anillos, comités, mesas de trabajo, ambientes, tertulias, núcleos, micro y macrocentros, hechos que dan razón no sólo de la cantidad sino también de la diversidad de organizaciones en las que participan los maestros y maestras colombianos.

\section{Una mirada contextual a las redes como formación y potenciación de sujetos}

El siguiente apartado busca explicar y complementar los enunciados anteriores, a partir de las reflexiones suscitadas desde las experiencias vivas de interacciones de los maestros organizados en red, específicamente del departamento de Santander ${ }^{8}$, como producto de la mirada y del análisis generado a partir de las siguientes preguntas: ¿Cuál es el sentido y los intereses de los colectivos de maestros? ¿Qué buscan transformar? ¿Se potencian otras capacidades? ¿Otras maneras de ser maestro?

\subsection{Sentidos e intereses de los colectivos de maestros}

Etimológicamente interés significa lo que esta entre, aquello que conecta dos cosas distantes, la intención, la lucha, la preocupación y el trabajo hacia el logro de un objeto o fin deseado. El sentido se define como la construcción simbólica que realiza un actor social del objetivo de su acción. Así como en la sociedad red, "el sentido se organiza en torno a una identidad primaria" (Castells 28), en las redes de maestros se gesta a partir de un deseo o necesidad compartida con otros pares que da lugar a acciones también compartidas, que no son necesariamente impuestos o externos a su propia realidad, sino surgidos de sus reflexiones. Por ello, la calidad y magnitud de dichos intereses hace posible cohesionar a los sujetos deseantes, sostenerse y superar barreras de espacio y tiempo. Digamos entonces que el sentido no viene dado, surge y se otorga con base en las propias reflexiones, interpretaciones y necesidades, a partir de lo deseado; para el

encuentro se realizó en Santa Marta en julio de 2001. Las Redes pedagógicas del Caribe, la Red de innovaciones del suroccidente, los colectivos de Santander, las redes de Bogotá -como la Red de lenguaje, El anillo de matemáticas, las redes de Suba, entre otras- dan cuenta de esta realidad. Para ampliar cifras, los 15 números de la revista Nodos y Nudos de la Red CEE de la Universidad Pedagógica Nacional.

${ }^{8}$ Esta mirada se realizó con 18 colectivos y redes de maestros del departamento de Santander, que para su estudio se organizan en 5 categorías: 1) Mesas de trabajo por la calidad de la educación. La figura de mesas nace con el propósito de intervenir en formulación de políticas educativas, buscan ganar espacios en las instancias de toma de decisiones. Citamos, entre éstas, las mesas provinciales de Vélez, Guanentá y Comunera; municipales: mesa de Floridablanca; temáticas: mesa de educación media técnica de la provincia comunera. 2) Colectivos de investigación educativa: integrados por maestros y maestras que promueven y asumen la investigación como estrategia para cualificar las prácticas pedagógicas. Citamos, entre éstos, la Comisión de investigación educativa del Magdalena Medio de Barrancabermeja -Ciemm-, y el Colectivo de maestros investigadores de la Universidad de la Paz -Unipaz-. 3) Redes y equipos: se trata de grupos de maestros que se convocan especialmente para fortalecer su práctica pedagógica en un campo específico, como la Red de educación religiosa -ERE-, el Grupo de educación matemática, de la UIS, la Red de educación ambiental, la Red de Psicorientadoras de las provincias Guanentina y Comunera y la Red de maestros preescolares de García Rovira y del municipio de Floridablanca, equipos de maestras de apoyo a alumnos con necesidades educativas especiales de Bucaramanga, entre otros. 4) Microcentros de escuelas rurales: modalidad que se implementó como una de las estrategias del programa Escuela Nueva, si bien algunos conservan la misma dinámica con que fueron creados hace más de doce años, otros se han reinventado y se convierten en potencial semilla para nuevas miradas. Participaron los microcentros de los municipios de Zapatoca y de Málaga. 5) Asociaciones: como la asociación de orientadores escolares, de directivos docentes, de directores de núcleo, cuya finalidad es la autoformación y la defensa de derechos gremiales. 
caso de las redes pedagógicas, el sentido se construye desde los intereses de los grupos de maestros.

Para contextualizar los hallazgos, el siguiente gráfico da cuenta de los intereses de los colectivos de maestros que participaron como población sujeto de esta investigación en el departamento de Santander y que en la referencia anterior se enunciaron:

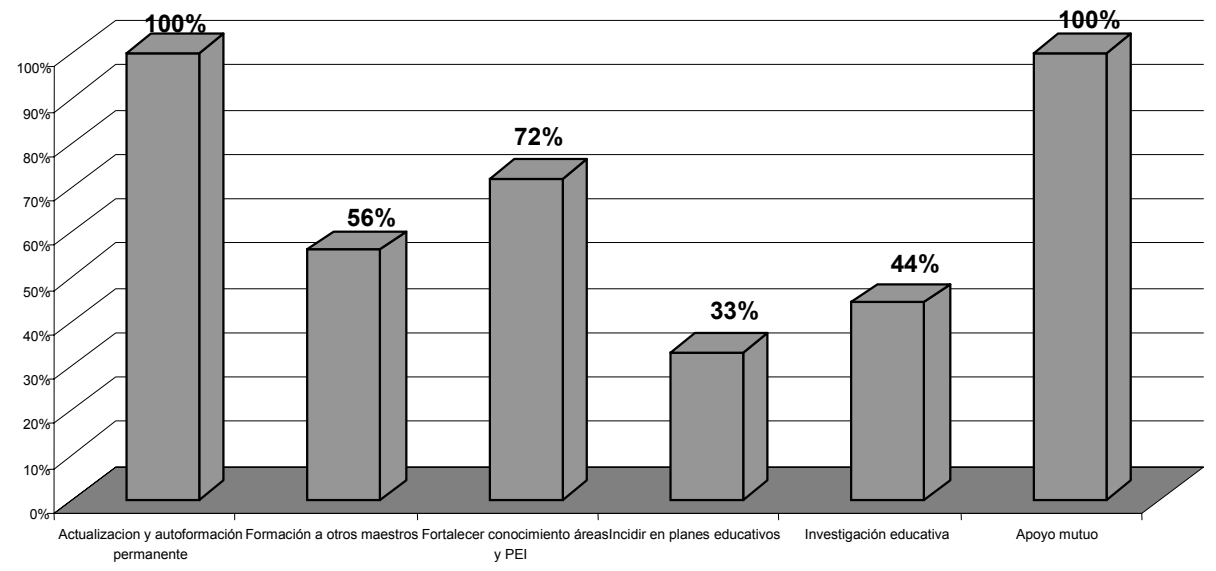

Gráfico 1. Sentido e intereses de los colectivos de maestros de Santander

Los sentidos manifiestos más relevantes son: formación permanente, expresada en procesos de autoformación, formación a otros maestros, construir conocimiento, aportar al mejoramiento de procesos educativos y apoyo mutuo, que se lee como una necesidad de fortalecer la dimensión socioafectiva y volitiva.

\subsection{La formación permanente de los maestros: una acción en la vida cotidiana}

El hecho de que la totalidad de maestros señalen como primer interés cualificarse, autoformarse, hace innegable un asomo de mentalidades que incorporan los conceptos de autorresponsabilidad, autocrecimiento y autorreconocimiento, que, a su vez, generan un empoderamiento como sujetos de saber. La autoformación se ve como una manera de fortalecerse para un mejor ejercicio de su labor, interés que no es sólo para beneficio individual sino que busca extenderse a otros, un $56 \%$ desarrolla, además, formación con otros maestros.

Para mayor comprensión, ilustremos con sus voces algunas de estas motivaciones:

Yo creo que el encuentro entre maestros funciona como formación porque al encontrarme con otros maestros me enriquece, el saber qué está haciendo el otro e intercambiar con él me anima a mejorar (Red de matemáticas)

Nosotros necesitamos encontrarnos para saber cómo vamos y para ayudarnos; la soledad es muy grande (Maestros rurales).

... hay gente que sabe manejar algunos programas y nosotros sabemos manejar otros, unos vienen y otros vamos, así intercambiamos. Uno se va encontrando, no siempre con los que tenemos más cerca porque no comparten nuestro lenguaje y nuestros intereses (...) los maestros de matemáticas de Bucaramanga se unieron con los de Socorro y 
Guanentá, ellos vienen a compartir sus adelantos y no necesitamos que nadie nos dé permiso o nos invite. Asistimos porque nos interesa (Red de matemáticas).

Cuando uno como maestro empieza a interactuar con otros colegas y se da cuenta que está haciendo actividades que el otro también las está haciendo y que le están dando resultados y que de pronto puede pulir o completar lo que le hace falta, entonces se atreve a hacer cambios, porque cuando uno lo ha visto es distinto que cuando le dicen: usted que tiene que cambiar su metodología, innovar, y uno empieza a hacerse la pregunta ¿y cómo lo hago? Si yo no he visto a nadie que lo haga, a nadie que le dé resultados, es más difícil cambiar. Precisamente los que estamos acá... somos aquellos que nos hemos atrevido a vencer ese miedo y a decir, yo no sé mucho, pero me reúno con los otros y ellos saben más que yo y nos fortalecemos ${ }^{9}$.

Los fragmentos anteriores son ilustrativos tanto de los avances en la formación y actualización que se genera en los colectivos de maestros que comienzan a asumirse en la vida cotidiana a manera de encuentros, como de la necesidad de contar con quien compartir y aclarar angustias y temores. Cuando un maestro expresa, "uno crece cuando se ve en los otros, cuando encuentra que hacen lo que uno hace o quiere hacer, eso anima y dan ganas de seguir", se produce un reconocimiento de su responsabilidad, que es a la vez un acto de afirmación que le da confianza y le anima a resistir para sostenerse en los procesos que considera válidos aunque las normas vayan en otra dirección.

Ahora bien, si la cultura está hecha de vida cotidiana y el campo de trabajo de la educación es la cultura, es entonces en la cotidianidad donde suceden la formación de los hábitos y los cambios de la cultura docente. Valga aquí recordar a Dewey cuando expresaba:

... no podemos olvidar que todos poseemos muchos hábitos de cuyo alcance no tenemos conciencia, porque se formaron sin nuestro conocimiento. Por consiguiente, son ellos los que nos poseen a nosotros, más que nosotros a ellos. Nos mueven y nos dominan. A menos que conozcamos lo que realizan y podamos juzgar el valor del resultado, no los dominaremos (1998: 37).

En la red, cada encuentro se convierte en un acto de mirarse al espejo para acicalarse, porque desde ahí los maestros comienzan a recuperar o dibujar una imagen distinta de sus modos de ser y hacer pedagogía; "se asumen como sujetos en construcción, constructores, de poder y con poder"10, capaces de pensar y proponer nuevas maneras de ser y actuar. En las interacciones se propicia la opción de reflexionar sobre la cotidianidad de la práctica pedagógica que muchas veces se torna mecánica; el acto de discutirla, compararla, contrastarla, sumarle otras voces y ponerla en diálogo con teorías, hace que sucedan o emerjan modos de cualificación contextualizados y propuestas realizables porque van revestidas no de un deber ser sino de un puedo y quiero hacer, aquello que he construido con otros o que ya ha sido experimentado por ellas y ellos mismos.

\subsection{La circulación de saberes y el aprendizaje dialógico constituyentes de lo colectivo}

Los planteamientos actuales de las ciencias sociales que realizan autores como Habermas (1999), Beck (1998), Castells (2000), Touraine (1997), expresan que el

\footnotetext{
${ }^{9}$ Conclusiones de uno de los encuentros intercolectivos realizados como parte de esta investigación, que además de los diálogos y grupos de discusión intracolectivos, provocó encuentros intercolectivos.

${ }_{10}$ Voces del Tercer Encuentro Iberoamericano de Colectivos y Redes de maestros. Santa Marta, julio de 2002.
} 
aprendizaje en la actual sociedad de la información depende cada vez más del conjunto de interacciones que se producen con los sujetos, textos y contextos con los que estamos relacionados. Así, entonces, transformar las interacciones es mejorar los saberes y crecer como sujetos, porque en la interacción emerge el deseo de salir de sí, de intersubjetivarse; allí se potencia como sujeto colectivo y sucede el aprendizaje dialógico y cooperativo. Surge también la necesidad de compartir con los otros, de crear otras formas de aprender y de enseñar, de producir saber y de interactuar con los contextos. Todo esto desdibuja el distanciamiento individuo-sociedad para fortalecer al sujeto individual $y$ colectivo vinculado a su realidad social, capaz de actuar transformándola.

Lo colectivo se hace en la acción reflexionada, allí se contrastan discursos y acciones, y por eso es el lugar para transformar la práctica. El acto de aprender a trabajar en equipo, a perder el miedo a preguntar, la capacidad de reconocer al otro como par académico, el afecto y la solidaridad que se suscitan, son señales del avance en esta dirección. La solidaridad, asumida como uno de los principios del aprendizaje dialógico (Flecha, 2000) se asegura si desde la base surgen unos valores compartidos; éstos hacen que los discursos de la convivencia y el pacifismo pasen del plano discursivo a la vivencia. El compartir, la amistad, los afectos, que se señalan como uno de los principales intereses de los colectivos, hacen que veamos estos colectivos como semilla potencial para unas relaciones más solidarias y cooperativas, y para un fortalecimiento del sujeto colectivo.

\section{Los intereses transformadores y la resignificación de la noción de calidad}

Los siguientes fragmentos, tomados de viva voz en diferentes momentos de interacción, dan cuenta de que los colectivos son lugares para la afirmación y el reconocimiento del ser maestro, lugares en los que es posible vencer el miedo para arriesgarse a cambiar sus métodos, ensayar otras prácticas, construirse y afirmarse como sujetos potentes:

A la pregunta por sus intereses, surgen expresiones como:

Hacer fácil la matemática para enseñar a pensar y a resolver problemas (Grupo de matemática); potenciar la formación de maestros para mejorar la calidad de vida de los estudiantes a fin de hacer efectivo el mandato de no más escuelas pobres para pobres (Fe y Alegría); apoyar la flexibilización de las escuelas para la integración de niños y niñas con necesidades educativas especiales (Maestras de apoyo); intervenir donde se toman las decisiones, participar en la formulación de los planes educativos y hacer gestión para que la educación aporte al desarrollo regional (Mesas de trabajo).

Todas ellas manifiestan de sus intencionalidades transformadoras, si se toma como referencia de análisis la cotidianidad en que se ha instalado el quehacer de los maestros. Intervenir en el diseño de políticas, por ejemplo, es asumir conscientemente que la educación tiene además una clara connotación social y política, y esto configura otro lugar para el maestro.

Yo tengo un interés prioritario que es casi un compromiso sagrado con lo que hemos sido nosotras durante estos seis años, que el Plan Decenal de Floridablanca sea una realidad como mandato del concejo. La mesa actúa como espacio de interlocución y encuentro con otras realidades que no están en mis manos (Mesa Floridablanca).

(...) Nosotras al principio de año trabajamos doble, trabajamos en las mañanas en nuestros colegios y por la tarde sabemos que, sin convocarnos, llegamos al encuentro, porque si no estudiamos, si no planeamos colectivamente, si no elaboramos los proyectos incluyendo los aspectos mal evaluados, no estaríamos avanzando" (Red Psicorientadoras). 
Me parece superimportante lo que hace el coordinador de la mesa de San Gil, lleva una lectura cada vez que nos reunimos y la explica, y eso como que va acrecentando más los conocimientos y lo hace más interesante para que uno diga la próxima vez tengo que haber leído; no se obliga pero uno va porque ya se siente ese cariño de pertenecer a esa comunidad y va acrecentando toda esa serie de conocimientos (Mesa de San Gil).

Yo creo que otra cosa que hemos aprendido es el conocimiento sociopolítico de nuestro medio, por ejemplo, elaborar los Planes de Ordenamiento Territorial implica que le paguen a una persona para que haga la parte del componente educativo y nosotros nos quedamos aislados; yo creo que ese es un lugar para que nosotros mismos nos involucremos y hacer caminar los proyectos que están en el papel o en el banco de proyectos. Esto es fundamental; el maestro es muy reacio cuando se le invita a reuniones para definir la política educativa del municipio, lo general es que se responda que vayan otros, eso a mí no me corresponde (...) hemos empezado a enterarnos qué dicen los Planes de Desarrollo en materia de educación (...) a acercarnos a definir lo que se impone en un municipio, ahí tenemos que estar los maestros (Mesa Floridablanca).

Sin duda, estas voces reflejan de otros modos de pensarse como sujetos y de asumir su papel, una apertura a otros campos de saber y de actuar que resignifican los modos instaurados de ser maestro. Dan cuenta también de una transformación de la noción de calidad educativa que tanto se ha debatido y que en la actualidad se ha reducido a una racionalidad instrumental sostenida sólo en criterios de eficacia y eficiencia. Subyace y emerge una calidad con otros atributos, calidad que se construye, que no se impone ni se importa, porque no se trae de afuera ni tampoco se requiere que otros vengan a dictarla o inyectarla, sino que se asume como proposición diaria: "Todo lo que hago día a día ha de ser con la mejor calidad: los materiales educativos, los contenidos elegidos, el ambiente de clase, mi propia disposición como educador, las tareas elegidas, todo ha de ir intencionalmente dotado de un sello de lo mejor para los estudiantes que se están formando bajo mi responsabilidad". La calidad en lo que se hace, pasa en primer lugar por la intención, segundo por la decisión y tercero por la responsabilidad que es también compartida con la institución y otras instancias.

Calidad para los maestros de estos colectivos significa también incluir y asumir en la vida cotidiana otros principios que guíen la acción, generar un clima institucional favorable, anexar en sus agendas programas de actualización y mejoramiento permanentes, trabajar por proyectos, compartir los resultados, evaluar los alcances y aprender de los errores, y esto se logra en el día a día y en el propio contexto. De esta manera, la calidad que se está definiendo está cruzada por la de libertad académica, vista como la posibilidad de ser y dejar ser, mediada por una acción pedagógica y por condiciones de equidad y reconocimiento de singularidades, concepto que en el trabajo colectivo se ve como posibilidad de vivenciar el mandato freiriano Nadie aprende solo, todos aprendemos en comunidad, porque sólo en común-unidad construimos la comunidad y la sociedad imaginada.

\section{Emergen otros maestros: maestros del límite, sujetos políticos}

Es evidente que aquí está emergiendo otro tipo de maestros, diferentes a los de los diagnósticos del Ministerio y de otros sectores que continúan clasificándolos como transmisores. Los maestros y maestras de los colectivos pedagógicos se están formando como sujetos colectivos y están logrando estar en el límite; son maestros del borde en los 
términos planteados por Martínez ${ }^{11}$, con capacidad de tomar distancias del centro, para pensarse en contexto y no dejarse atrapar exclusivamente por las lógicas establecidas. Maestros del límite porque han superado las barreras del no se puede, hay que esperar que nos den permiso, que nos llamen o nos ordenen... Maestros que han sobrepasado el tiempo escolar y el horario de clase, el libro de texto, el currículo establecido, que olvidaron las excusas de eso a mí no me corresponde, yo cumplo sólo con lo mío, y se han volcado abiertamente, por decisión propia, a reinventar formas de ganarle al tiempo, a las normas que limitan y aniquilan. Son maestros y maestras que asumen otros sentidos para la escuela, y trabajan por construir lo humano; por ello dan lugar al contexto donde están situados, a las preguntas de sus alumnos para contrastarlas con lo que les viene dado; maestros que se atreven a pensar en lo cotidiano, en sus diferencias y también más allá de lo impuesto, a bordear el límite para llegar a lo impensado, a la creación.

Estar en el límite es reconocerse como cruzador de fronteras, que al decir de Giroux en Cruzando fronteras, es aquel sujeto capaz de un diálogo productivo con otros, de producir espacios en el que "esas prácticas, ideologías y relaciones sociales dominantes que eliminan la especificidad del otro se deben cuestionar y superar"; "cruzar la frontera significa que los profesores y otros intelectuales hacen problemáticas y dejan otras, las fronteras culturales, teóricas, ideológicas que los encierran dentro de la seguridad"; significa también arriesgarse a leer y descubrir la historia y las tradiciones, no con actitud de sumisión, reverencia y continuidad perpetua, sino con actitud crítica para retomar o dejar lo necesario en cada contexto y en cada situación.

Cruzar las fronteras para estar en el límite y trascender el lugar de lo establecido significa sobrepasar la ritualización de los tiempos, los horarios y otros legados de la escuela de Comenio, superar la acción obligada y mecánica y pasar a la acción contextualizada, reflexionada y fundamentada en los lugares concretos, porque es ahí donde se posibilita y "afronta el trabajo intelectual en su especificidad y parcialidad, en el marco de un discurso de descubrimiento y construcción" (123). Los maestros que se organizan y actúan en colectivo promueven el ser cruzadores de frontera porque al en-redarse se asumen y afirman como productores de saber y potencian su capacidad para hacer el tránsito de funcionarios, portadores, reproductores y administradores de currículos al de productores de saber pedagógico y de otra sociedad. Sin intentar homogeneizar, digamos que los colectivos se convierten en dispositivo y campo para estas transformaciones del maestro: más político, más sujeto.

\section{6. ¿Cuáles son las capacidades que se están potenciando?}

El siguiente cuadro sintetiza y da cuenta de algunas de las capacidades que se están potenciando y afirmando en los maestros vinculados a redes y colectivos. Las he categorizado en: pedagógicas, administrativas y de gestión, volitivas, socioafectivas y sociopolíticas.

\footnotetext{
${ }^{11}$ El texto citado de Martínez Boom, et al. (2001), desarrolla la categoría de maestros del borde, para referirse a un estadio en que los maestros y maestras son capaces de estar en movimiento para no dejarse atrapar ni agobiar por las lógicas impuestas. Estas construcciones han sido posibles a partir de los hallazgos de la Expedición.
} 


\begin{tabular}{|c|c|c|c|}
\hline Pedagógicas & $\begin{array}{l}\text { Administrativas y } \\
\text { de gestión }\end{array}$ & $\begin{array}{l}\text { Socio afectivas y } \\
\text { volutiva }\end{array}$ & Sociopolíticas \\
\hline $\begin{array}{l}\text { Redimensión } \\
\text { tiempo del } \\
\text { hora- clase, hora- } \\
\text { reloj; se trabaja por } \\
\text { proyectos y se } \\
\text { comprometen } \\
\text { otras acciones. }\end{array}$ & $\begin{array}{l}\text { Habilidad para } \\
\text { intercambiar } \\
\text { experiencias, } \\
\text { establecer alianzas. }\end{array}$ & $\begin{array}{lrr}\text { Deseo } & \text { de } \\
\text { superación y de } \\
\text { cualificar el trabajo } \\
\text { pedagógico. Mayor } \\
\text { valoración de su } \\
\text { profesión. }\end{array}$ & $\begin{array}{l}\text { Liderazgo colectivo } \\
\text { y compromiso social } \\
\text { con las } \\
\text { comunidades, más } \\
\text { allá de la tarea } \\
\text { escolar. }\end{array}$ \\
\hline $\begin{array}{lrr}\text { Enseñar y } & \text { aprender } \\
\text { como } & \text { proceso } \\
\text { resultante } & \text { del } \\
\text { intercambio } & \text { de } \\
\text { saberes con } & \text { sus } \\
\text { pares y } & \text { otros } \\
\text { actores. } & & \end{array}$ & $\begin{array}{lr}\begin{array}{l}\text { Capacidad } \\
\text { hacer }\end{array} \text { alianzas, } \\
\text { realizar } & \text { viajes, } \\
\text { conexiones, } & \\
\text { relaciones con otros } \\
\text { maestros } \\
\text { instituciones. }\end{array}$ & $\begin{array}{l}\text { Resistencia, } \\
\text { voluntad y } \\
\text { persistencia en sus } \\
\text { propósitos y aquello } \\
\text { que consideran } \\
\text { legítimo para su } \\
\text { trabajo y contexto. }\end{array}$ & $\begin{array}{l}\text { Ampliación de la } \\
\text { mirada para realizar } \\
\text { lectura y postura } \\
\text { crítica frente a las } \\
\text { contrarreformas } \\
\text { educativas. }\end{array}$ \\
\hline 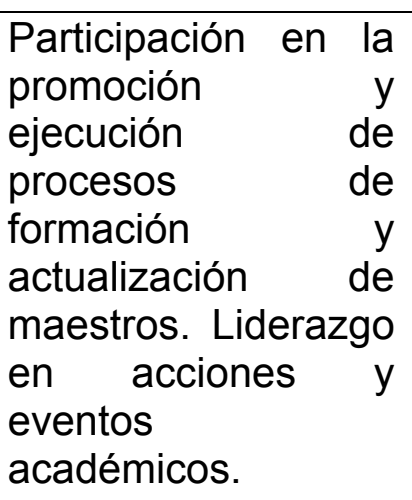 & $\begin{array}{l}\text { Mayor compromiso } \\
\text { con su trabajo y con } \\
\text { su contexto. } \\
\text { Decisión para crear } \\
\text { organizaciones, } \\
\text { extender su saber y } \\
\text { ofrecer servicios. }\end{array}$ & $\begin{array}{l}\text { Incremento de la } \\
\text { autonomía; mayor } \\
\text { capacidad para } \\
\text { decidir por sí mismo. }\end{array}$ & $\begin{array}{l}\text { Mayor sensibilidad } \\
\text { ante los problemas } \\
\text { socioeducativos y } \\
\text { preocupación por } \\
\text { buscar alternativas. }\end{array}$ \\
\hline $\begin{array}{lc}\text { Desarrollo } & \text { de } \\
\text { proyectos } & \\
\text { pedagógicos } & \text { con } \\
\text { actuaciones } & \text { más } \\
\text { allá del aula. } & \end{array}$ & $\begin{array}{l}\text { Capacidad para } \\
\text { hacer consultas al } \\
\text { MEN y otras } \\
\text { instancias } \\
\text { gubernamentales e } \\
\text { instituciones. Mayor } \\
\text { arrojo, interés por } \\
\text { verificar. }\end{array}$ & $\begin{array}{l}\text { Perder el miedo a } \\
\text { intervenir en público, } \\
\text { a publicar, a } \\
\text { comunicar, } \\
\text { expresar } \\
\text { pensamientos } \\
\text { propios. }\end{array}$ & $\begin{array}{l}\text { Mayor conocimiento } \\
\text { del país, región y } \\
\text { contexto local; se } \\
\text { amplía } \\
\text { sensibilidad social. }\end{array}$ \\
\hline $\begin{array}{l}\text { Liderazgo en el } \\
\text { diseño y puesta en } \\
\text { marcha } \\
\text { propuestas } \\
\text { alternativas. Cambia } \\
\text { para de } \\
\text { cambios. promover }\end{array}$ & $\begin{array}{l}\text { Promoción del } \\
\text { trabajo en equipo y } \\
\text { participación en } \\
\text { grupos } \\
\text { interdisciplinarios } \\
\text { dentro y fuera de la } \\
\text { institución. }\end{array}$ & $\begin{array}{l}\text { Crecimiento } \\
\text { personal } \\
\text { interpersonal, } \\
\text { mejoramiento en el } \\
\text { manejo de } \\
\text { relaciones, } \\
\text { reconocimiento del } \\
\text { otro como par. } \\
\text { Ampliación de su } \\
\text { círculo } \\
\text { amistades. }\end{array}$ & $\begin{array}{l}\text { Arrojo y decisión } \\
\text { para intervenir en } \\
\text { las esferas de } \\
\text { decisión } \\
\text { formulación } \\
\text { políticas educativas. }\end{array}$ \\
\hline
\end{tabular}

Fuente: Organización autónoma de la autora a partir de la mirada investigativa. 
7. ¿Se están construyendo otras identidades de maestro y maestra? ¿De qué compromiso se habla?

Las expresiones anteriores dan pistas para proponer que en los colectivos están emergiendo entidades proyecto, en el sentido que señala Castells, para referirse a "los actores sociales [que] basándose en los saberes y las realidades culturales de que disponen, construyen una nueva identidad que redefine su posición en la sociedad y, al hacerlo, buscan la transformación de toda la estructura social" (30). Los colectivos o redes pedagógicas actúan como lugares cotidianos desde los cuales es posible que los maestros se transformen y, simultáneamente, generen transformaciones pedagógicas y culturales.

El compromiso del maestro que aquí se enuncia está cargado de significación, no es sólo un lugar común sino una comprensión del sentido educativo y de lo público reconocidos como asunto propio, una resignificación de los modos de ser maestro que tradicionalmente aparecen desvalorizados y que minimizan su condición. Se trata de un crecimiento individual y a la vez colectivo que sucede en escenarios construidos autogestionariamente, no impuestos; crecimiento que es estructurante del sujeto mismo y de los procesos que agencia. Estructurante porque se potencian capacidades de actuación para el maestro, más allá de lo adoptado históricamente en el sentido expresado por Freire, en La naturaleza política de la educación: "Solo en una perspectiva histórica en la que hombres y mujeres sean capaces de reinventar el mundo en una dirección ética y estética más allá de los patrones que están ahí, tiene sentido discutir la comunicación en la nueva etapa de la continuidad del cambio y de la innovación" (1996: 40).

8. ¿Es posible asumir los colectivos y redes pedagógicas como escenarios de constitución de subjetividades políticas?

Tomando como argumento las siguientes premisas: i) en ningún otro periodo de la historia de este país se requiere con tanta urgencia la participación directa de actores sociales, y entre ellos la de maestros y maestras, en la reconstrucción de lo público y en la definición y el desarrollo de políticas públicas; ii) todo acto educativo es un acto político, y por tanto, todos los educadores somos sujetos públicos y políticos, y hacemos política al hacer educación $^{12}$, y iii) el individuo es potencialmente un sujeto político ${ }^{13}$, puedo afirmar que cuando los maestros asumen y adoptan una conciencia de organización y de trabajo colectivo, desde el cual potencien pensamiento y acción críticos en defensa y promoción de lo público y de mejoramiento de las condiciones socioeducativas, connotan y configuran nuevas formas de hacer política. De igual manera, cuando asumen el aula y la escuela como lugares de la micropolítica y como microespacios de poder, éstos se convierten en escenario político primario y fundacional de subjetividades políticas, si esta intención y estos saberes son comprensibles para el maestro.

Pero si esta intencionalidad no se hace evidente en los propósitos, las actividades, los temas objeto de estudio que selecciona el maestro, y en la necesaria resignificación de los presaberes con que llegan los estudiantes, si todo esto no se reconstruye -discute,

\footnotetext{
12 La teoría de Freire sobre la educación desarrolla ampliamente esta premisa, y "lo político aquí exige libertad, posibilidad de elección, de autonomía" (Política y educación, 12-13).

${ }^{13}$ Desde Aristóteles se plantea que el hombre en un animal político. Para Morin, desde una perspectiva biológica, el individuo es simultáneamente producto y productor de un ciclo de reproducción. Digamos entonces que su constitución en sujeto le exige potenciación de capacidades y dimensiones mediadas por actos sociocognitivos y de interacción social, en los cuales intervienen multiplicidad de factores: simbólicos, culturales, ideológicos, históricos, políticos.
}

Digitalizado por RED ACADEMICA 
reflexiona, cuestiona, critica- y recontextualiza en el aula, podríamos decir que no se potencia el desarrollo de la dimensión política del sujeto; más bien, se incrementa la formación de individuos apolíticos, individualistas, o "antisujetos", como los llama Touraine. Valga decir, indiferentes, desesperanzados ante la posibilidad de otra sociedad y otras condiciones sociales. En este contexto, lo que hace la red o colectivo es posibilitar al maestro ampliar su mirada, documentarse, aprender de otras experiencias, fortalecer sus propias capacidades y modos de ser político para mejorar su actuación política.

Así, la mirada a las redes de maestros y maestros, especialmente a las experiencias que tienen directa relación con las políticas educativas, da cuenta de maestros que se están atreviendo a repensar su práctica y sus interacciones en el aula, las instituciones y la comunidad; digamos que se están afirmando como sujetos políticos. Y si asumimos aquí el concepto de sujeto que plantea Touraine "como el esfuerzo y el deseo del individuo de ser actor", es decir, sujetos con capacidad de ser interlocutores, generadores y constructores de cambios socioeducativos, podemos decir que muchos maestros de las redes utilizan las políticas actuales para impulsar sus propias iniciativas, trascienden la norma para dar paso a lo alternativo y, a la vez que posibilitan su transformación como sujetos, transforman sus prácticas. Son maestros que se sitúan en el límite, en el sentido ya enunciado, y actúan en conjunto porque en colectivo fortalecen su resistencia a las normas que arrasan su dignidad y su condición de educadores, y se arriesgan a proponer y reinventar otras maneras de interpretarlas y de aplicarlas, a definir y construir currículos pertinentes al contexto y a las exigencias de formación de los educandos aunque las directivas impongan otras miradas. Todos estos, son modos de agenciamiento de lo político.

\section{A manera de cierre}

En el recorrido del texto se ha hecho manifiesto que el trabajo colectivo ha permitido a los maestros construir una dinámica de autoformación mediada por el interés y el afecto, avanzar en el conocimiento del contexto y en la generación de propuestas que respondan a problemáticas reales, generar sinergia y crear expectativa para la vinculación de nuevos maestros y maestras a los colectivos, asumir posturas críticas, hacer propuestas que superen las fronteras de la escuela establecidas culturalmente, intervenir en otros escenarios de poder y en la formulación de políticas educativas, ampliar las relaciones interinstitucionales, interdisciplinarias, intersectoriales para fortalecerse como sujeto político individual y colectivo.

Considero que estas realidades no pueden pasar desapercibidas si se contrastan con multitud de críticas a los programas externos y jerárquicos de formación de maestros y con la problemática enunciada en el primer apartado. Se hace necesario reconocer y potenciar los grupos existentes como posibilidad de aprender de estas experiencias a fin de ampliar y generar estrategias de sostenibilidad -académica, política, comunicativa, administrativa-, que sin privarlas de su singularidad ni arrasar su condición autónoma de organización y actuación, les posibilite incrementar su autonomía y creatividad. Esa es la semilla que tenemos para los nuevos movimientos sociales y culturales, y esa es la tarea que hoy nos convoca y nos ocupa. 


\section{Referencias Bibliografícas}

Arendt, Hannah. ¿Qué es la política? Barcelona: Paidós, 1997.

Beck, U. La sociedad del riesgo. Barcelona: Paidós, 1998 (1986).

Castells, Manuel. El poder de la identidad. Madrid: Alianza Editorial, 2000.

Dabas, Elina. Redes sociales, familia y escuela. Buenos Aires: Paidos, 1998.

Dewey, J. Democracia y educación. Madrid: Morata, 1998.

Edwards R. Verónica y Tapias, G. "Redes desde la sociedad civil: Propuestas para su potenciación", en Revista La Piragua, No. 11. Chile: CEAL, 1995.

Expedición Pedagógica Nacional. Huellas y registros. Bogotá: UPN, 2001.

Flecha, Ramón. Aprendizaje dialógico. Barcelona: CREA, Paidós, 2000.

Freire, Paulo. La naturaleza política de la educación. Barcelona: Paidós, 1996. Política y educación. Madrid: Siglo XXI, 1997.

Guidens, A. Modernidad e identidad del yo. Barcelona: Península (1991).

Giroux, Henry. Placeres inquietantes. Aprendiendo de la cultura popular. Barcelona: Paidós, 1996.

Habermas, J. La inclusión del otro. Barcelona: Paidós, 1999 (1996)

Martínez, A, Mejía, M. y Unda, P. El itinerario del maestro: de portador a productor de saber pedagógico. Bogotá: UPN- Expedición pedagógica Nacional-Fundación Restrepo Barco, 2002.

Martínez, Alberto y Unda, Pilar. "Redes Pedagógicas: otro modo de ser conjuntos", en Revista Nodos y Nudos, No. 3. Bogotá: UPN, 1997.

"Maestro Sujeto de Saber y Prácticas de Cualificación", en Revista Colombiana de Educación, No. 31. Bogotá: UPN, 1995.

Martínez, Maria Cristina. "Los colectivos pedagógicos de maestros y el agenciamiento de la acción política", en Organizaciones pedagógicas de maestros, Vol. 3. Bogotá: Magisterio-UPN, 2002.

Morin, Edgar. "La noción de sujeto", en La cabeza bien puesta. Repensar la reforma, reformar el pensamiento. Buenos Aires: Nueva Visión, 2001.

"Colectivos de maestros de Santander: un modo de estar en el límite", en Pretextos para soñar la educación para el Santander que queremos, Boletín No. 14. Bucaramanga: Comité Expedición Pedagógica, 2002.

Touraine, A. ¿Podremos vivir juntos? Iguales y diferentes. Barcelona: PCC, 1997.

UPN. Tercer encuentro Iberoamericano de colectivos y redes de maestros que hacen investigación desde la escuela. Bogotá: Memorias, UPN, OEI, 2003. 